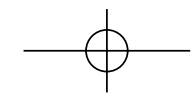

\title{
18
}

\section{The Wisdom of Nature: An Evolutionary Heuristic for Human Enhancement}

\author{
Nick Bostrom and Anders Sandberg*
}

\begin{abstract}
Human beings are a marvel of evolved complexity. Such systems can be difficult to enhance. When we manipulate complex evolved systems, which are poorly understood, our interventions often fail or backfire. It can appear as if there is a "wisdom of nature" which we ignore at our peril. Sometimes the belief in nature's wisdom - and corresponding doubts about the prudence of tampering with nature, especially human nature-manifest as diffusely moral objections against enhancement. Such objections may be expressed as intuitions about the superiority of the natural or the troublesomeness of hubris, or as an evaluative bias in favor of the status quo. This chapter explores the extent to which such prudence-derived anti-enhancement sentiments are justified. We develop a heuristic, inspired by the field of evolutionary medicine, for identifying promising human enhancement interventions. The heuristic incorporates the grains of truth contained in "nature knows best" attitudes while providing criteria for the special cases where we have reason to believe that it is feasible for us to improve on nature.
\end{abstract}

\section{Introduction}

1.1. The wisdom of nature, and the special problem of enhancement

We marvel at the complexity of the human organism, how its various parts have evolved to solve intricate problems: the eye to collect and pre-process

* Oxford Future of Humanity Institute, Faculty of Philosophy and James Martin 2 Ist Century School, Oxford University. Forthcoming in Enhancing Humans, ed. Julian Savulescu and Nick Bostrom (Oxford: Oxford University Press)

published in Human Enhancement (Oxford University Press, 2009), ed. J. Savulescu \& N. Bostrom: pp. 375-416 
visual information, the immune system to fight infection and cancer, the lungs to oxygenate the blood. The human brain - the focus of many of the most alluring proposed enhancements - is arguably the most complex thing in the known universe. Given how rudimentary is our understanding of the human organism, particularly the brain, how could we have any realistic hope of enhancing such a system?

To enhance even a system like a car or a motorcycle - whose complexity is trivial in comparison to that of the human organism - requires a fair bit of understanding of how the thing works. Isn't the challenge we face in trying to enhance human beings so difficult as to be hopelessly beyond our reach, at least until the biological sciences and the general level of human abilities have advanced vastly beyond their present state?

It is easier to see how therapeutic medicine should be feasible. Intuitively, the explanation would go as follows: Even a very excellently designed system will occasionally break. We might then be able to figure out what has broken, and how to fix it. This seems much less daunting than to take a very excellently designed, unbroken system, and enhance it beyond its normal functioning.

Yet we know that even therapeutic medicine is very difficult. It has been claimed that until circa I900, medicine did more harm than good. ${ }^{1}$ And various recent studies suggest that even much of contemporary medicine is ineffectual or outright harmful. ${ }^{2}$ Iatrogenic deaths account for 2 to 4 percent of all deaths in the US (the third leading cause of death according to one accounting ${ }^{3}$ ) and may correspond to a loss of life expectancy by 6 to I 2 months. ${ }^{4}$ We are all familiar with nutritional advice, drugs, and therapies that were promoted by health authorities but later found to be damaging to health. In many cases, the initial recommendations were informed by large clinical trials. When even therapeutic medicine, based on fairly good data from large clinical trials, is so hard to get right, it seems that a prudent person has much reason to be wary of purported enhancements, especially as the case for such enhancements is often based on much weaker data. Evolution is a process powerful enough to have led to the development of systems — such as human brains - that are far more complex and capable than anything that human scientists or engineers have managed to design.

1 McKeown and Lowe I974.

2 Newhouse and Group. I993; Frech and Miller I996; Kirsch, Moore, Scoboria, and Nicholls 2002.

3 Starfield $2000 . \quad{ }^{4}$ Bunker $200 \mathrm{I}$. 
Surely it would be foolish, absent strong supporting evidence, to suppose that we are currently likely to be able to do better than evolution, especially when so far we have not even managed to understand the systems that evolution has designed and when our attempts even just to repair what evolution has built so often misfire!

We believe that these informal considerations contain a grain of truth. Nonetheless, in many particular cases we believe it is practically feasible to improve human nature. The evolution heuristic is our explanation of why this is so. If the evolution heuristic works as we suggest, it shows that there is some validity to the widespread intuition that nature often knows best, especially in relation to proposals for human enhancement. But the heuristic also demonstrates that the validity of this intuition is limited, by revealing important exceptional cases in which we can hope to improve on nature using even our present or near-future science and technology.

The evolution heuristic might be useful for scientists working to develop enhancement technologies. It might also be useful in evaluating beliefs and arguments about the ethics of human enhancement. This is because intuitions about the wisdom of nature appear to play an important role in the cognitive ecology of many anti-enhancement advocates. While sophisticated bioconservatives (aware of the distinction between "is" and "ought") may not explicitly base their arguments on the alleged wisdom in nature, we believe that such intuitions influence their evaluation of the plausibility of various empirical assumptions and mid-level moral principles that are invoked in the enhancement discourse; just as the opinions and practical judgments of the pro-enhancement transhumanists look more plausible if one assumes that nature is generally unwise. Addressing such hidden empirical background assumptions may therefore help illuminate important questions in applied ethics. ${ }^{5}$

\subsection{The evolution heuristic}

The basic idea is simple. In order to decide whether we want to modify some aspect of a system, it is helpful to consider why the system has that aspect in the first place. Similarly, if we propose to introduce some new feature, we might ask why the system does not already possess it.

\footnotetext{
${ }^{5}$ On the role of mid-level principles in one area of applied ethics, see Beauchamp and Childress
} I979. 


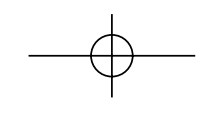

The system of concern here is the human organism. The question why the human organism has a certain property can be answered on at least two different levels, ontogeny and phylogeny. Here the focus is on the phylogeny of the human organism.

We can conceive of a proposed enhancement as an ordered pair $(\alpha, A)$, where $\alpha$ is some specific intervention (e.g., the administration of a drug) and $A$ is the trait that the intervention is intended to realize (e.g., improved memory consolidation). We define an enhancement as an intervention that causes either an improvement in the functioning of some subsystem (e.g. long-term memory) beyond its normal healthy state in some individual or the addition of a new capacity (e.g. magnetic sense).

On this definition, an enhancement is not necessarily desirable, either for the enhanced individual or for society. For instance, we might have no reason to value an enhancement of our sweat glands that increases their ability to produce perspiration in response to heat stimuli. In other instances, we might benefit from increased functionality or a new capacity, and yet not benefit from the enhancement because the intervention also causes unacceptable side-effects. ${ }^{6}$ The evolution heuristic is a tool to help us think through whether some proposed enhancement is likely to yield a net benefit.

The starting point of the heuristic is to pose the evolutionary optimality challenge:

(EOC) If the proposed intervention would result in an enhancement, why have we not already evolved to be that way?

Suppose that we liken evolution to a surpassingly great engineer. (The limitations of this metaphor are part of what makes it useful for our purposes.) Using this metaphor, the EOC can be expressed as the question, "How could we realistically hope to improve on evolution's work?" We propose that there are three main categories of possible answers, which can be summarized as follows:

- Changed tradeoffs. Evolution "designed" the system for operation in one type of environment, but now we wish to deploy it in a very different type of environment. It is not surprising, then, that we might

${ }^{6}$ Which side-effects are acceptable depends, of course, on the benefits resulting from the enhancement, and these may vary between subjects depending on their goals, life plans, and circumstances. 
be able to modify the system better to meet the demands imposed on it by the new environment. Making such modifications need not require engineering skills on a par with those of evolution: consider that it is much harder to design and build a car from scratch than it is to fit an existing car with a new set of wheels or make some other tweaks to improve functioning in some particular setting, such as icy roads. Similarly, the human organism, whilst initially "designed" for operation as a hunter-gatherer on the African savannah, must now function in the modern world. We may well be capable of making some enhancing tweaks and adjustments to the new environment even though our engineering talent does not remotely approach that of evolution.

- Value discordance. There is a discrepancy between the standards by which evolution measured the quality of her work, and the standards that we wish to apply. Even if evolution had managed to build the finest reproduction-and-survival machine imaginable, we may still have reason to change it because what we value is not primarily to be maximally effective inclusive-fitness optimizers. This discordance in objectives is an important source of answers to the EOC. It is not surprising that we can modify a system better to meet our goals, if these goals differ substantially from the ones that (metaphorically might be seen as having) guided evolution in designing the system the way she did. Again, this explanation does not presuppose that our engineering talent exceeds evolution's. Compare the case to that of a mediocre technician, who would never be able to design a car, let alone a good one; but who may well be capable of converting the latest BMW model into a crude rain-collecting device, thereby enhancing the system's functionality as a water collecting device.

- Evolutionary restrictions. We have access to various tools, materials, and techniques that were unavailable to evolution. Even if our engineering talent is far inferior to evolution's, we may nevertheless be able to achieve certain things that stumped evolution, thanks to these novel aids. We should be cautious in invoking this explanation, for evolution often managed to achieve with primitive means what we are unable to do with state-of-the-art technology. But in some cases one can show that it is practically impossible to create a certain feature without some particular tool-no matter how ingenious the engineer-while the 
same feature can be achieved by any dimwit given access to the right tool. In these special cases we might be able to overcome evolutionary restrictions.

In the following three sections, we will explore each of these categories of possible answers to the EOC in more detail, and show how they can help us decide whether or not to go ahead with various potential human enhancements.

Our ideas about enhancement in many ways parallel earlier work in evolutionary medicine. Evolutionary medicine is based on using evolutionary considerations to understand aspects of human health. ${ }^{7}$ Hosts and parasites have adapted to one another, and analysis of the tradeoffs involved can reveal adaptations that contributed to fitness in the past but are maladaptive today, or symptoms that have been misdiagnosed as harmful but may actually aid recovery. Evolutionary medicine also helps explain the incidence of genetic diseases, which can be maintained in the population because of beneficial effects in historically normal environments. Another contribution of evolutionary medicine has been to draw attention to the fact that our modern environment may not always fit a biology designed for Pleistocene conditions, and how this mismatch can cause disease. These insights are recycled in our analysis of human enhancement.

Another strand of research relevant to our aims is evolutionary optimization theory, which seeks to determine the abilities and limitations of evolution in terms of producing efficient biological functions. ${ }^{8}$ While, naively, evolution might be thought to maximize individual fitness (the expected lifetime number of surviving offspring), there are many contexts in which this simplification leads to error. Sometimes it is necessary to focus on the concept of inclusive fitness, which takes into account the effects of a genotype on the fitness of blood-relatives other than direct descendants. Sometimes a gene-centric perspective is needed, to account for phenomena such as segregation distortion and junk DNA. ${ }^{9}$ There are also many other ways in which evolution routinely falls short of "optimality", some of which will be covered in later sections.

\footnotetext{
7 Williams and Nesse I99I; Trevathan, Smith and McKenna I999.

${ }^{8}$ Parker and Smith I990. 9 Dawkins I976; Williams I996/I966.
} 


\section{Changed tradeoffs}

\subsection{General remarks on tradeoffs}

Evolutionary adaptation often involves striking a tradeoff between competing design criteria. Evolution has fine-tuned us for life in the ancestral environment, which, for the most part, was a life as a member of a hunter-gatherer tribe roaming the African savannah. Life in contemporary society differs in many ways from life in the environment of evolutionary adaptedness. Modern conditions are too recent for our species to have fully adapted to them, which means that the tradeoffs evolution struck may no longer be optimal today.

In evolutionary biology, the "environment of evolutionary adaptedness" (EEA) refers not to a particular time or place, but to the environment in which a species evolved and to which it is adapted. ${ }^{10}$ It includes both inanimate and animate aspects of the environment, such as climate, vegetation, prey, predators, pathogens, and the social environment of conspecifics. We can also think of the EEA as the set of all evolutionary pressures faced by the ancestors of the species over recent evolutionary time - in the case of humans, at least 200,000 years. ${ }^{11}$ Hunting, gathering of fruits and nuts, courtship, parasites, and hand-to-hand combat with wild animals and enemy tribes were elements of the EEA; speeding cars, high levels of trans fats, concrete ghettos, and tax return forms were not.

The import of this for the evolution heuristic is that even if the human organism were a wonderfully well-designed system for life in the EEA, it may not in all respects be well designed for life in contemporary society. If we can identify specific changes to our environment that have shifted the optimal tradeoff point between competing design desiderata in a certain direction, we may be able to find relatively easy interventions that could "retune" the tradeoff to a point that is closer to its present optimum. Such retuning interventions might be among the low-hanging fruits on the enhancement tree, fruits within reach even in the absence of super-advanced medical technology.

$$
{ }^{10} \text { Hagen 2002. } \quad 11 \text { Hagen } 2002 .
$$


Proposed enhancements aiming to retune altered tradeoffs can often meet the EOC. The new trait that the enhancement gives us might have been maladaptive in the EEA even though it would be adaptive now. Alternatively, the new trait might be intrinsically associated with another trait that was maladaptive in the EEA but has become less disadvantageous (or even beneficial) in the modern environment, so that the terms of the tradeoff have shifted. In either case, the enhancement could be adaptive in the current environment without having been so in the EEA, which would explain why we do not have that trait, allowing us to meet the EOC.

We can roughly distinguish two ways in which tradeoffs can change: new resources may have become available that were absent, or available only at great cost, in the EEA; or, the demands placed on one of the subsystems of the human organism may have changed since we left the EEA. Let us consider these two possibilities in turn and look at some examples.

\subsection{Resources}

One of the main differences between human life today (for most people in developed countries) and life in the EEA is the abundant availability of food independently of place and season. In the state of nature, food is relatively scarce much of the time, making energy conservation paramount and forcing difficult energy expenditure tradeoffs between metabolically costly tissues, processes, and behaviors. As we shall see, increased access to nutrients suggests several promising enhancement opportunities. We have also gained access to important new non-dietary resources, including improved protection against physical threats, obstetric assistance, better temperature control, and increased availability of information. Let us examine how these new resources are relevant to potential enhancements of the brain and the immune system.

2.2.1. The brain The human brain constitutes only 2 per cent of body mass yet accounts for about 20 per cent of total energy expenditure. Combined, the brain, heart, gastrointestinal tract, kidneys, and liver consume 70 per cent of basal metabolism. This forces tradeoffs between the size and capacity of these organs, and between allocation of time and energy to activities other than searching for food in greater quantity or quality. ${ }^{12}$

\footnotetext{
12 Aiello, Bates and Joffe 200 I; Fish and Lockwood 2003.
} 
Unsurprisingly, we find that, in evolutionary lineages where nutritional demands are high and cognitive demands low (such as bats hunting in uncluttered environments), relative brain size is correspondingly smaller. ${ }^{13}$ In humans, brain size correlates positively with cognitive capacity $(. \approx$ 0.33)..$^{14}$

Holding brain mass constant, a greater level of mental activity might also enable us to apply our brains more effectively to process information and solve problems. The brain, however, requires extra energy when we exert mental effort, reducing the normally tightly regulated blood glucose level by about 5 per cent $(0.2 \mathrm{mmol} / \mathrm{l})$ for short $(<\mathrm{I} 5 \mathrm{~min})$ efforts and more for longer exertions. ${ }^{15}$ Conversely, increasing blood glucose levels has been shown to improve cognitive performance in demanding tasks. ${ }^{16}$

The metabolic problem is exacerbated during prenatal and early childhood growth where brain development requires extra energy. Brain metabolism accounts for a staggering 60 per cent of total metabolism in newborns, ${ }^{17}$ exacerbating the competitive situation between mother and child for nutritional resources - an unpleasant tradeoff. ${ }^{18}$ Children with greater birth weight have a cognitive advantage. ${ }^{19}$

Another constraint on prenatal cerebral development is the size of the human birth canal (itself constrained by bipedalism), which historically placed severe constraints on the head size of newborns. ${ }^{20}$ These constraints are partly obviated by modern obstetrics and the availability of caesarian section. One way of reducing head size at birth and perinatal energy demands would be to extend the period of postnatal maturation. However, delayed maturation was vastly riskier in the EEA than it is now.

What all this suggests is that cognitive enhancements might be possible if we can find interventions that recalibrate these legacy tradeoffs in ways that are more optimal in the contemporary world. For example, suppose we could discover interventions that moderately increased brain growth during gestation, or slightly prolonged the period of brain growth during infancy, or that triggered an increase in available mental energy. Applying the EOC to these hypothetical interventions, we get a green light. We can

\footnotetext{
${ }_{13}$ Niven 2005. $\quad{ }^{14}$ McDaniel 2005.

15 Scholey, Harper and Kennedy 200I; Fairclough and Houston 2004.

${ }_{16}$ Korol and Gold I998; Manning, Stone, Korol and Gold I998; Martin and Benton I999; Meikle, Riby and Stollery 2005. Increasing oxygen levels (another requirement for metabolism) also improves cognition (Winder and Borrill I998).

${ }_{17}$ Holliday I986. $\quad{ }^{18}$ Martin I996. $\quad{ }^{19}$ Matte 200I. $\quad{ }^{20}$ Trevathan I987.
} 


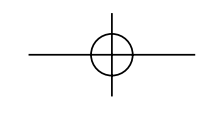

see why these enhancements would have been maladaptive in the EEA, and why they may nevertheless have become entirely beneficial now that the underlying tradeoffs have changed as a result of the availability of new resources. If the "downside" of getting more mental energy is that we would burn more calories, many of us would pounce at the opportunity.

Not all cognitive enhancement interventions get an immediate green light from the above argument. Stimulants like caffeine and Modafinil enable increased wakefulness and control over sleep patterns. ${ }^{21}$ But sleep serves various (poorly understood) functions other than to conserve energy. ${ }^{22}$ If the explanation for why we do not sleep less than we do has to do with these other functions, then reducing sleep might well have more problematic side-effects than increasing the amount of calories we need to consume. For any particular intervention, such as the administration of some drug, we also of course need to consider the possibility of contingent side-effects, i.e. that the drug might have effects on the body other than simply retuning the target tradeoff.

2.2.2. The immune system While the immune system serves an essential function by protecting us from infection and cancer, it also consumes significant amounts of energy. ${ }^{23}$ Experiments have found direct energetic costs of immune activation. ${ }^{24}$ In birds immune activation corresponded to a 29 per cent rise of resting metabolic rate ${ }^{25}$ and in humans the rate increases by 13 per cent per degree centigrade of fever. ${ }^{26}$ In addition, the protein synthesis demands of the immune system are sizeable yet prioritized, as evidenced by a 70 per cent increase in protein turnover in children during infection despite a condition of malnourishment. ${ }^{27}$ One would expect the immune system to have evolved a level of activity that strikes a tradeoff between these and other requirements - a level optimized for life in the EEA but perhaps no longer ideal.

Such a tradeoff has been proposed as part of an explanation of the placebo effect. ${ }^{28}$ The placebo effect is puzzling because it apparently involves getting something (accelerated recovery from disease or injury) for nothing (merely

\footnotetext{
21 Caldwell 200I. $\quad{ }^{22}$ Siegel $2005 . \quad{ }^{23}$ McDade 2003.

${ }^{24}$ Demas, Chefer, Talan and Nelson I997; Moret and Schmid-Hempel 2000; Ots, Kerimov, Ivankina, Ilyina and Horak $200 \mathrm{I}$.

${ }^{25}$ Martin, Scheuerlein and Wikelski 2003. $\quad{ }^{26}$ Elia 1992.

27 Waterlow I984; McDade 2003. ${ }^{28}$ Humphrey 2000.
} 
having a belief). If the subjective experience of being treated causes a healthpromoting response, why are we not always responding that way? Studies have shown that it is possible chemically to modulate the placebo response down ${ }^{29}$ or up. ${ }^{30}$

One possible explanation is that mobilizing the placebo effect consumes resources, perhaps through activation of the immune system or other forms of physiological health investment. Also, to the extent that the placebo response reduces defensive reactions (such as pain, stiffness, and inflammation), it might increase our vulnerability to future injury and microbial assaults. If so, one might expect that natural selection would have made us such that the placebo response would be triggered by signals indicating that in the near future we will (a) recover from our current injury or disease (in which case there is no need to conserve resources to fight a drawn-out infection and less need to maintain defensive reactions), (b) have good access to nutrients (in which case, again, there is no need to conserve resources), and (c) be protected from external threats (in which case there is less need to keep resources in reserve for immediate action readiness). Consistent with this model, the evidence does indeed show that the healing system is activated not only by the expectation that we will get well soon but also by the impression that external circumstances are generally favorable. For example, social status, ${ }^{31}$ success, having somebody looking after us, ${ }^{32}$ sunshine, and regular meals might all indicate that we are in circumstances where it is optimal for the body to invest in healing and long-term health, and they do seem to prompt the body to do just that. By contrast, conflict, ${ }^{33}$ stress, anxiety, uncertainty, ${ }^{34}$ rejection, isolation, and despair appear to shift resources towards immediate readiness to face crises and away from building long-term health.

If this model of the placebo response is correct, several potential avenues of enhancement are worth exploring. One is that since physical safety and reliable access to food are much improved compared to the EEA, it might now be beneficial to invest more in biological processes that build long-term health than was usually optimal in the EEA. We might thus inquire whether the placebo effect and other evolved responses are flexible

\footnotetext{
29 Sauro and Greenberg 2005. $\quad 30$ Colloca and Benedetti 2005 .

${ }^{31}$ Sapolsky 2005. $\quad{ }^{32}$ House, Landis and Umberson I988.

33 Kiecolt, Glaser, Cacioppo, MacCallum, Snydersmith, Kim and Malarkey I997.

${ }^{34}$ McDade 2002.
} 
enough to have adjusted the level of health investment to a level that is optimal under modern conditions. If not, we could benefit from an intervention that triggers a placebo-like response or otherwise increases the body's health investment.

However, while external stresses and resource constraints are reduced in the modern environment, the danger of auto-immune reactions remains. We would therefore have to be careful not to overshoot the target. It is possible that we would benefit from a lower baseline immune activity in some parts of the immune system since we are now less at risk of dying from infectious diseases. As an example, the hygiene theory of allergic diseases claims that the reduction in immunological challenge in particular from helminth parasites during early life increases the risk of allergic disease later in life. ${ }^{35}$ If true, then a down-regulation of a particular dendritic cell subpopulation (DC2) sensitive to helminths, but causing allergic reactions, might be desirable. Alternatively, an up-regulation of regulatory (DCreg) cells that tend to be lost in unstimulated immune systems might be used to control the DC2 cells.

The evolution heuristic also leads us to consider other potential immune system enhancements. Even if the average activation level of our immune systems were still optimal in the modern era, we now possess more information (a new resource) about the detailed requirements in specific situations. We can use this information to override our bodies' natural response tendencies. For example, recipients of donated organs can benefit from immunosuppressant drugs. Conversely, a patient with early-stage cancer might be better off if her immune system could be induced to mount an immediate all-out assault on the incipient tumor instead of conserving resources for hypothetical future challenges. ${ }^{36}$

A more radical enhancement would be to improve DNA repair, which would reduce cancer-causing mutations and improve radiation resistance, at the price of increasing metabolic needs. The modification could be achieved through overexpression of existing DNA repair genes ${ }^{37}$ or perhaps even by transgenic incorporation of the unique abilities of Deinococcus radiodurans. ${ }^{38}$

\footnotetext{
35 Yazdanbakhsh, Kremsner and van Ree 2002; Maizels 2005.

36 Boon and van Baren 2003; Dunn, Old and Schreiber 2004.

37 Wood, Mitchell, Sgouros and Lindahl $200 \mathrm{I}$.

38 Battista, Earl and Park I999; Venkateswaran, McFarlan, Ghosal, Minton, Vasilenko, Makarova, Wackett and Daly 2000.
} 
Increased repair would have to be balanced with apoptosis and replacement of irreparably damaged cells (another energy cost). Until recently, increased DNA repair activity might have been too metabolically costly and mutationprone for evolution to consider it a worthwhile bargain. One of the most well-studied pathways, the PARP-I pathway, protects the genome from damage but requires so much energy that it can damage cells through energy depletion. ${ }^{39}$

Since the objective of the interventions suggested above is to restore health, one could argue that they should be regarded as therapeutic rather than enhancing. But these classifications are not necessarily incompatible. We could regard the interventions as therapeutic for the subsystems whose functioning has been deteriorated by disease, yet enhancing for the immune system, whose functioning is improved beyond its normal state. ${ }^{40}$

\subsection{Demands}

Just as we have many resources that were denied our hunter-gatherer ancestors, we also face a different set of demands than they did. This suggests further opportunities for enhancement.

Changes in demands on the human organism occur when old demands disappear or are reduced (e.g. less need for long treks to get food; hygienic surroundings reducing demands on the immune system), and when demands grow in strength or new demands arise (e.g. greater need to be able to concentrate on abstract material for long periods; new pathogens spreading in larger societies). The source and nature of a particular demand may also change. For instance, exercise is no longer necessary to gain sustenance, but is instead needed to maintain the body in good shape.

Many "diseases of civilization" are due to these changed demands. For example, our ancestors needed to exert themselves physically to secure adequate nutrition, whereas our easy access to abundant food can lead to obesity. People working indoors do not get the sun exposure that our ancestors had, leading to vitamin D deficiency; ${ }^{41}$ yet we risk skin cancer when we expose pale skin to the sun during occasional recreational

\footnotetext{
39 de Murcia and Shall 2000; Skaper 2003.

${ }^{40}$ In like manner, we can view vaccinations as both therapeutic (or more accurately, prophylactic) and as enhancing.

41 Thomas, Lloyd-Jones, Thadhani, Shaw, Deraska, Kitch, Vamvakas, Dick, Prince and Finkelstein I998.
} 


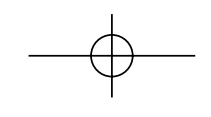

activities. Rapid blood coagulation was beneficial in the past, when there was a high risk of wounding. The increased risk for cardiovascular problems and embolisms was an acceptable tradeoff. Today, the risk of wounding has sharply decreased, making the downsides relatively more important. Reducing coagulation, e.g. by taking low-dose aspirin, can be beneficial given these changed demands, ${ }^{42}$ although we risk incidental side-effects such as stomach irritation.

While the change in demands can cause or exacerbate problems, it can also alleviate them. The recent emergence of the IT industry appears to have produced a refuge for people with Asperger's syndrome where their preference for structure and detail becomes a virtue and their problems with face-to-face communication less of a disadvantage. ${ }^{43}$ Deliberate fitting of environments to human evolutionary adaptations and individual idiosyncrasies is a promising adjunct to direct human enhancement for improving human performance and wellbeing.

2.3.1. Literacy and numeracy Intellectual capacity, or at least some specific forms of it, seem to have become more rewarded in contemporary society than they were in the EEA. There is a positive correlation in Western society between IQ and income. ${ }^{44}$ Higher levels of general cognitive ability are important not just for highly demanding, high status jobs, but also for success in everyday life, such as being able to fill out forms, understand news, and maintain health. As society becomes more complex, these demands increase, placing people of low cognitive ability at a greater disadvantage. ${ }^{45}$ While general cognitive ability may have been advantageous (and selected for) in our evolutionary past, ${ }^{46,}{ }^{47}$ numeracy and literacy represent more specific abilities whose utility has increased dramatically in recent times.

Before the invention of writing, the human brain faced no pressure to be literate. In the current age, however, literacy is in very high demand. Failing to meet this demand places an individual at a severe disadvantage

\footnotetext{
${ }^{42}$ Force 2002. $\quad{ }^{43}$ Silberman 2001.

${ }^{44}$ Neisser, Boodoo, Bouchard, Boykin, Brody, Ceci, Halpern, Loehlin, Perloff, Sternberg and Urbina I996; Gottfredson I997; Bersaglieri, Sabeti, Patterson, Vanderploeg, Schaffner, Drake, Rhodes, Reich and Hirschhorn 2004.

${ }^{45}$ Gottfredson I997; Gottfredson 2004. $\quad{ }^{46}$ Gottfredson 2007.

47 It should be noted that IQ correlates negatively with fertility in many modern societies (Udry 1978; Vancourt and Bean I985; Vining, Bygren, Hattori, Nystrom and Tamura I988). This might be an example of value discordance between human values and evolutionary fitness.
} 
in modern society. Since writing is a relatively recent invention $(3,500$ $\mathrm{BC}$ ), and since it is even more recently that written language has become such a dominant mode of communication, it is plausible that the human brain is not optimized for modern conditions. The fact that the neural machinery needed for writing and reading largely overlaps with that needed to produce and interpret oral communication means that the mismatch between evolved capacity and present demands is not as great as it might have been. Nevertheless, as the phenomenon of dyslexia demonstrates, it is possible to have deficits in language processing that are relatively specific to written language, possibly arising from minor variations in phonological processing. ${ }^{48}$ Dyslexia also appears to be linked to enhanced or atypical visuospatial abilities. ${ }^{49}$ These abilities might have been useful in the EEA, but today literacy is usually more important for achieving life goals. If our species had been using written language for a couple of million years and reproductive fitness had depended on literacy, dyslexia might have been much rarer than it is.

Modern society also places much greater demands on advanced numerical skills than we faced in the EEA. In hunter-gatherer societies, numeracy demands appear to have been limited to being able to count to five or ten..$^{50}$ In the modern world, one is at a major disadvantage if one cannot understand at least basic arithmetic. Many occupations require a grasp of statistics, calculus, geometry, or higher mathematics. Programming skills open up additional employment possibilities. Good logical and analytical skills create further opportunities in our information-dense, technologymediated, and generally formalized modern society. These skills were much less useful in the Pleistocene.

The altered nature of the demands we face suggests opportunities for enhancement by readjusting tradeoffs that are no longer optimal. For example, number relations appear to be handled by brain circuits closely linked to spatial cognition of external objects, and affected by spatial attention abilities. ${ }^{51}$ Hence enhancement of this type of spatial attention, ${ }^{52}$ possibly at the expense of remote or peripheral attention, could be a useful enhancement. Similarly, enhancements in reading ability at the

\footnotetext{
48 Goulandris, Snowling and Walker 2000.

49 von Karolyi, Winner, Gray and Sherman 2003; Brunswick, Martin, Marzano and Savill 2007.

50 Pica, Lemer, Izard and Dehaene 2004

51 McCord 2000; Hubbard, Piazza, Pinel and Dehaene 2005. $\quad{ }^{52}$ Green and Bavelier 2006.
} 
expense of the dyslexia-related visuospatial abilities might gain support from the EOC.

2.3.2. Concentration The importance of being able to concentrate on abstract thinking and tasks with little sensory feedback has increased significantly in modern times relative to the importance of peripheral awareness. In the EEA, peripheral awareness was crucial for detecting predators and enemies, while an ability to exclude other stimuli had few applications. We may hence have evolved attention systems with a tendency to be too easily distracted in a modern setting. It has been suggested that ADHD is a form of "response-readiness" that was more adaptive in past environments. ${ }^{53}$ Concentration enhancers may therefore be feasible and promising in modern settings, enabling users to meet high demands for sustained attention. Drugs such as methylphenidate (Ritalin) are already used to treat ADHD and occasionally also for enhancement purposes. ${ }^{54}$

2.3.3. Dietary preferences and fat storage One tradeoff involving food availability relates to the question of how much nutrition the body should store in fatty deposits. If high-calorie foods are scarce and food availability highly variable, it is optimal for an individual to crave high-calorie foods and to store lots of energy in fat deposits as insurance against lean times. We still need an appetite today, and we still need fat deposits, but - at least in the developed world - they are much less important now than in the past. Many people's natural set-points of appetite and body fat are higher than optimal, leading to increased morbidity. In wealthy modern societies, where a Mars bar is never far away, the risks of obesity and diabetes outweigh the risk of under-nutrition, ${ }^{55}$ and a sweet tooth is maladaptive.

This suggests that it might be possible to enhance human health by finding effective ways to down-regulate our cravings for fat and sugar, or by reducing the absorption and storage of these calories in fatty tissues. Such an enhancement might take various forms: nutritional advice, diet pills, artificial sweeteners, indigestible substances that taste like fat, weightloss clubs, hypnotherapy, and, in the future, gene therapy. The evolution heuristic suggests that our natural proclivities to consume and store nutrients

\footnotetext{
53 Jensen, Mrazek, Knapp, Steinberg, Pfeffer, Schowalter and Shapiro I997.

${ }^{54}$ Farah, Illes, Cook-Deegan, Gardner, Kandel, King, Parens, Sahakian and Wolpe 2004

55 Fontaine, Redden, Wang, Westfall and Allison 2003.
} 
might be a case where we could benefit from going against the wisdom of nature. Independent considerations and possibly further research would be needed to determine the most effective way of doing this, given that weight loss itself is a longevity risk factor ${ }^{56}$ and that those who are mildly overweight have lower mortality than those who are underweight or obese. ${ }^{57}$ Possibly an aversion to unhealthy foods and eating habits would be more effective and safer than a general down-regulation of appetite. The heuristic tells us only that there are no general "wisdom of nature" reasons to retain our current bodyweight set-points; it does not by itself tell us which approaches to changing them would be safest.

\subsection{The interplay between resources and demands}

The picture is complicated by the fact that some phenomena zigzag across the two subcategories of changed tradeoffs (resources and demands). Transport vehicles and machinery are new resources that reduce the demand for physical exertion. The effect is that most of us get less exercise in the course of our daily routines. Yet our bodies appear to be designed for physical activity, so a sedentary life causes a variety of health problems. New resources (gyms, exercise equipment, parks, jogging clubs) have been developed to help us overcome the problems of a sedentary lifestyle. But now a new demand arises: we need the energy and self-motivation to make use of these resources - a demand that many find it difficult to meet.

In a case like this, there are multiple potential intervention points where a change could result in an improvement of our lives. One approach would be to design our environment in such a way as to force us to be more physically active. Elevators could be removed, motor vehicles banned from certain areas, and so forth. Another approach would be to attempt to redesign our bodies so that they would not be dependent on frequent physical exertion to remain healthy. On this approach, we might try to develop pharmaceuticals that trigger effects in the body similar to those normally caused by exercise (such as the IGF-I/MGF signaling pathways, which are stimulated by exercise or muscle damage). ${ }^{58}$ Yet another approach would be to attempt interventions that increase our energy and self-motivation, thereby making it easier for us to exercise on our own

\footnotetext{
56 Gaesser I999. $\quad{ }^{57}$ Flegal, Graubard, Williamson and Gail 2005.

58 Baldwin and Haddad 2002; Goldspink 2005.
} 
initiative. For instance, there might be pharmaceuticals that would give us more energy or strengthen our willpower, or perhaps a habit of regular workouts instilled in childhood would carry over into adult life.

Whether any of these interventions will work, and, if so, which one would be the most effective and have the best balance of benefits over burdens, cannot be determined a priori. This is an empirical question, whose answer may depend on changing social circumstances, levels of technology, personal preferences, and other factors. One should note that it is not only biological interventions which can have undesirable side-effects. Removing elevators might cause some health benefits for people forced to climb the stairs, but it may also deny access for people with mobility impairments and cause unnecessary inconvenience to others. Encouraging high levels of physical activity in children might have overall health benefits but it might also lead to more injuries, more worn-out knees and hip joints later in life, and less time for non-physical activities.

Another illustration of the complex interplay between new resources and new demands is offered by the case of addictive drugs. Alcohol, heroin, and crack cocaine are comparatively novel resources. The availability of these resources create a new demand on the human organism: the ability to avoid becoming addicted to harmful drugs that hijack the brain's reward system. Individuals vary in how they metabolize these drugs and how their brains react to exposure. Again, the solution might be to develop new resources (e.g. detox clinics), temporary pharmacological interventions (methadone), permanent biological modifications (vaccines), educational initiatives (drug awareness programs), or social policies (criminalization). Alternatively, one might attempt to develop safer, non-addictive substitutes for harmful drugs. ${ }^{59}$ There are many possible ways to defy or to work around the wisdom of nature.

\section{Value discordance}

\subsection{General remarks on value discordance}

We have discussed opportunities for enhancement arising from the changed tradeoffs we face in the modern world compared to those of the EEA. (A 
great engineer built a system for use in a certain environment; we adapt it for use in a different environment.) In this section, we discuss another source of enhancement opportunities: the discordance between evolutionary fitness and human values. (A great engineer built a system that efficiently serves one purpose; we tinker with it to make it serve a different purpose.)

While our goals are not identical to those of evolution, there is considerable overlap. We value health, and health increases inclusive fitness. We value good eyesight, and good eyesight is useful for survival. We value musicality and artistic creativity, and these talents helped to attract mates in the EEA. If we are hoping to enhance some attribute for which the concordance in objectives is perfect, the present category will not give any help in meeting the EOC. We then either have to find an answer from one of the other categories or else suspect that what appears to be an easy enhancement will in fact come at a large hidden cost.

Whilst some of our traits are both valuable to us and conducive to fitness, many attributes that we value would either not have promoted inclusive fitness in our natural environment, or else would not have been fitness-promoting to a sufficient extent to result in a profile of traits that is optimal from the perspective of our own values. There is a plethora of capacities or characteristics to which we assign a value that exceeds the contribution these characteristics made to survival and reproduction.

One obvious example is contraceptive technology. Vasectomy, birth control pills, and other contraceptive methods enhance our control over our reproductive systems, severing the link between sex and reproduction. We may value such enhancements because they make family planning easier and increase choice. But evolution would frown on these practices. The great engineer would not regard the absence of an easy reproductive off-switch as a defect. When our goals differ from hers, it is unsurprising that we are able to modify her design in ways that make it better (by our lights) even if our design skills fall far short of hers. ${ }^{60}$

We can distinguish (at least) two distinct sources of such value discordance. The first is that the characteristics that would maximize an individual's inclusive fitness are nor always identical to the characteristics that would be best for her. The other is that the characteristics that would maximize

${ }^{60}$ Evolution might still have the last laugh if in the long run she redesigns our species to directly desire to have as many children as possible, or to have an aversion against contraceptives. Cultural "evolution" might beat biological evolution to the punch. 
an individual's inclusive fitness are not always identical to those that would be best for society, or impersonally best. If our goal is to identify potential interventions that individuals would have prudential reasons for wanting, then we may perhaps set aside the second source of value discordance. If, however, we are interested in addressing ethical and public policy matters, then it is relevant to consider value discordance arising from either of these two sources. Let us consider each in turn.

\subsection{Good for the individual}

What characteristics promote individual well-being? There is a vast ethical and empirical literature on this question, which we shall not attempt to review here. For our purposes, it will suffice to list (Table I) some candidate characteristics, ones which may with some plausibility be taken to be among those that contribute to individual well-being in a wide range of circumstances. This list is for illustration only. Other lists could be substituted without affecting the structure of our argument. ${ }^{61}$

Table I. Some traits that may promote individual well-being

- Emotional well-being

- Freedom from severe or chronic pain

- Friendship and love

- Long-term memory

- Mathematical ability

- Awareness and consciousness

- Musicality

- Artistic appreciation and creativity

- Literary appreciation

- Confidence and self-esteem

- Healthy pleasures

- Mental energy

- Ability to concentrate

- Abstract thinking

- Longevity

- Social skills

61 The items in the list need not be final goods. Characteristics that are mere means to more fundamental goods can be included. For example, even if one thinks that musicality or musical appreciation is not intrinsically good, one can still include them in the list if one believes that they tend-as a matter of empirical fact - to promote well-being (for example, by creating opportunities for enjoyment). 
To illustrate the idea, take mathematical ability. Suppose that we believe that having greater mathematical ability would tend to make our lives go better-perhaps because it would give us competitive advantages in the job market, perhaps because appreciating mathematical beauty is a value in itself, or perhaps because we believe that mathematical ability is linked to other abilities that would increase our well-being. We then pose the EOC: Why has evolution not already endowed us with more mathematical ability than we have?

It is possible that answers to this EOC may be found in the other categories we discuss in this chapter (changed tradeoffs or evolutionary restrictions). Yet suppose that is not so. We may then appeal to an answer in the value discordance category. Even if greater mathematical capacity would have been maladaptive in the EEA and even if it would still be maladaptive today, it may nevertheless be good for us, because the good for humans is different from what maximizes our fitness.

But we are not yet done. What the evolution heuristic teaches us in this case is that we must expect that the intervention will have some effect that reduces fitness. If we cannot form any plausible idea of what sort of effect the intervention might produce that would reduce fitness, then we must suspect that the intervention will have important effects that we have not understood. That should give us pause. A fitness-reducing effect that we have not anticipated might be something very bad, such as a serious medical side-effect. The EOC hoists a warning flag. If, however, we can give a plausible account of why the proposed intervention to increase mathematical ability would reduce fitness, and yet we judge this fitness-reducing effect as desirable or at least worth enduring for the sake of the benefit, then we have met the EOC.

This does not guarantee that the enhancement will succeed. It is still possible that the intervention will fail to produce the desired result or that it would have some unforeseen side-effect. There might be more than one sufficient reason why evolution did not already make this intervention to enhance mathematical ability. But once we have identified at least one sufficient reason, the warning flag raised by the EOC comes down. We have shown that one potential reason for thinking that the enhancement will fail (the "wisdom of nature" reason) does not apply to the present case.

As an example, evolution has not optimized us for happiness and has instead led to a number of adaptations that cause psychological distress and 
frustration. ${ }^{62}$ The "hedonic-treadmill" causes us quickly to adapt to positive experiences and to seek more, as goods we have gained become taken for granted as a new status quo. ${ }^{63}$ Sexual jealousy, romantic heartaches, status envy, competitiveness, anxiety, boredom, sadness and despair may have been essential for survival and reproductive success in the EEA, but they take a toll in terms of human suffering and may substantially reduce our wellbeing. An intervention that caused an upward shift in hedonic set-point, or that down-regulated some of these negative emotions, would hence meet the EOC: we can see why the effect would have been maladaptive in the EEA, and yet believe that we would benefit from these effects because of a discordance between inclusive fitness and individual well-being.

\subsection{Good for society}

Many characteristics that promote individual well-being also promote the social good, but the two lists are unlikely to be identical. Table 2 lists some candidate traits that might contribute to the good of society.

As with the list for individual well-being, this one is for illustration only. One could create alternative lists for various related questions, such as traits that are good for humanity as a whole, or for sentient life, or for

Table 2. Some traits that may promote the social good

- Extended altruism

- Conscientiousness and honesty

- Modesty and self-deprecation

- Originality, inventiveness, and independent thinking

- Civil courage

- Knowledge and good judgment about public affairs

- Empathy and compassion

- Nurturing emotions and caring behavior

- Just admiration and appreciation

- Self-control, ability to control violent impulses

- Strong sense of fairness

- Lack of racial prejudice

- Lack of tendency to abuse drugs

- Taking joy in others' successes and flourishing

- Useful forms of economic productivity

- Healthy longevity

${ }^{62}$ Buss $2000 . \quad{ }^{63}$ Diener, Suh, Lucas and Smith 1999. 
a particular community, or traits that specifically help us become better moral agents. While the lists may overlap, they will likely disagree about some characteristics or their relative importance. The evolution heuristic can be applied using any such list as input.

To use such a list with the EOC, we proceed in the same way as with the "good for the individual" source of value discordance. For example, we might have a drug that appears to make those who take it more compassionate. This might seem like a good thing, but why has evolution not already made us more compassionate? Presumably, evolution could easily have produced an endogenous substance with similar effects to the drug; so the likely explanation is that a higher level of compassionateness would not have increased inclusive fitness in the EEA. We may press on and ask $w h y$ it is that greater compassionateness would have been maladaptive in the EEA. One may surmise that such a trait would have been associated with evolutionary downsides - such as reduced ability credibly to threaten savage retaliation, a tendency to spare the lives of enemies allowing them to come back another day and reverse their defeat, an increased propensity to offer help to those in need beyond what is useful for reciprocity and social acceptance, and so forth. But these very effects, which would have made heightened compassionateness maladaptive for an individual in the EEA, are precisely the kinds of effects which we might believe would be beneficial for the common good today. We do not have to assume that the relevant trade-offs have changed since the EEA. Even in the EEA, it might have had net good effects for a local population of hunter-gatherers if one person was born with a mutation causing an unusually high level of compassionateness, even though that individual himself might have suffered a fitness penalty. If we accept these premises, then the hypothetical drug that increases compassionateness would pass the EOC. It would be a case where we have reason to think that the wisdom of nature has not achieved what would be best for society and that we could feasibly do better.

\section{Evolutionary restrictions}

4.1. General remarks on evolutionary restrictions

The final category of answers to the EOC focuses on the fact that there are certain limitations in what evolution can do. Using the "great engineer" 
metaphor, we may say that we can hope to achieve certain things with our ham-handed tinkering that stumped Evolution, because we have access to tools, materials, and techniques that the great ingenious engineer lacked.

Metaphors aside, we can identify several restrictions of evolution's ability to achieve fitness-maximizing phenotypes even in the EEA. These are important, because in some cases they will indicate clear limitations in the "wisdom of nature", and a fortiori cases where there is room for potentially easy improvements. At a high level of abstraction, we can divide these restrictions into three classes:

- Fundamental inability: evolution is fundamentally incapable of producing a trait $A$.

- Entrapment in local optimum: evolution is stuck in a local optimum that excludes trait $A$.

- Evolutionary lag: evolution of trait $A$ takes so many generations that there has not yet been enough time for it to develop.

These three classes, which are discussed in more detail in the following three subsections, are not sharply separate. For example, one reason why a trait may take a vast number of generations to develop is that it requires escaping from one or more local optima. And given truly astronomical time scales, even some traits that we shall regard as fundamentally beyond evolution's reach might conceivably have evolved. However, the three classes are distinct enough to deserve individualized attention.

\subsection{Fundamental inability}

Biology is limited in what it can build. DNA can only code for proteins, which have to act on moieties in a water-based cellular environment using the relatively weak chemical forces that a protein can muster. This makes it very unlikely that any terrestrial organism could produce diamond, for instance, since the synthesis of diamondoid structures requires significant energy. ${ }^{64}$ And while bacteria can produce microscopic metal crystals, ${ }^{65}$ there is no way to unite them into contiguous metal. Hence evolution

${ }^{64}$ Adding a carbon dimer to a diamond surface using a nanotechnological tool would take more than 6. I eV (Merkle and Freitas 2003), about 20 times more energy than is released by the ATP hydrolysis that powers most enzymatic actions.

${ }_{65}$ Klaus, Joerger, Olsson and Granqvist I999. 
cannot achieve diamond tooth enamel or a titanium skeleton, even if these traits would have improved fitness.

Examples can be multiplied. It is unlikely that evolution could have evolved high-performance silicon chips to augment neural computation, even though such augmentations might have provided important benefits. A theoretical design of artificial red blood cells has been published, calculating the performance of a potentially feasible physical structure for transporting oxygen and carbon dioxide in the blood. ${ }^{66}$ This design, which is not limited by the materials and pressures that can be achieved using biology, would enable performance far outside the range of natural red blood cells.

Radical departures from nature are apt to raise a host of separate questions regarding biocompatibility and functional integration with evolved systems. But at least there is no mystery as to why we would not already have evolved these enhancements even if they would have increased inclusive fitness in the EEA.

Enhancements that evolution is fundamentally incapable of producing can therefore meet the EOC. When invoking "fundamental inability", it is important to determine that the inability does not pertain merely to the specific means one intends to use to effect the enhancement. If evolution would have been able to employ some different means to achieve the same effect, the challenge would remain to explain why evolution has not achieved the enhancement using that alternative route.

\subsection{Entrapment in local optimum}

Evolution sometimes gets stuck on solutions that are locally but not globally optimal. A locally optimal solution is one where any small change would make the solution worse, even if some big changes might make it better.

Being trapped in a local optimum is especially likely to account for failure to evolve polygenic traits that are adaptive only once fully developed and incur a fitness penalty in their intermediary stages of evolution. In some cases, the evolution of such traits may require an improbable coincidence of several simultaneous mutations that might simply not have occurred among our finite number of ancestors. A crafty genetic engineer may be able to solve some of the problems that were intractable to blind evolution.

${ }^{66}$ Freitas I998.

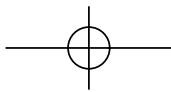


A human engineer can think backwards, starting with a goal in mind, working out what genetic modifications are necessary for its attainment.

The human appendix, a vestigial remnant of the caecum in other mammals, whilst having some limited immunological function, ${ }^{67}$ easily becomes infected. In the natural state appendicitis is a life-threatening condition, and is especially likely to occur at a young age. There is also evidence that surgical removal of the appendix reduces the risk of ulcerative colitis. ${ }^{68}$ It appears that removal of the appendix would have increased fitness in the EEA. However, a smaller appendix increases the risk of appendicitis. Carriers of genes predisposing for small appendices have higher risks of appendicitis than non-carriers, and, presumably, lower fitness. ${ }^{69}$ Therefore, unless evolution could find a way of doing away with the appendix entirely in one fell swoop, it might be unable to get rid of the organ; whence it remains. An intervention that safely and conveniently removed it might be an enhancement, increasing both fitness and quality of life.

Another source of evolutionary lock-in is antagonistic pleiotropy, referring to a situation in which a gene affects multiple traits in both beneficial and harmful ways. If one trait is strongly fitness-increasing and the other mildly fitness-decreasing, the overall effect is positive selection for the gene. ${ }^{70}$ One example is the $\varepsilon 4$ allele of apolipoprotein E. Having one or two copies of the allele increases the risk of Alzheimer disease in middle age but lowers the incidence of childhood diarrhea and may protect cognitive development. ${ }^{71}$ Antagonistic pleiotropy has also been discussed in relation to theories of ageing. The local optimum here is to retain the genes in question, but the global optimum would be to eliminate the antagonistic pleiotropy by evolving genes that specifically produced the beneficial traits without detrimental effects on other traits. Over longer timescales, evolution usually gets around antagonistic pleiotropy, for example by evolving modifier genes that counteract the negative effects, ${ }^{72}$ but such developments can take a long time and in the meanwhile a species remains trapped in a local optimum.

67 Fisher 2000.

${ }^{68}$ Koutroubakis and Vlachonikolis 2000; Andersson, Olaison, Tysk and Ekbom $200 \mathrm{I}$.

69 Nesse and Williams I 998.

${ }^{70}$ Leroi, Bartke, De Benedictis, Franceschi, Gartner, Gonos, Fedei, Kivisild, Lee, Kartaf-Ozer, Schumacher, Sikora, Slagboom, Tatar, Yashin, Vijg and Zwaan 2005.

71 Oria, Patrick, Zhang, Lorntz, Costa, Brito, Barrett, Lima and Guerrant 2005.

${ }^{72}$ Hammerstein I996. 
Yet another way in which evolution can get locked into a suboptimal state is exemplified by the phenomenon of heterozygote advantage. This refers to the common situation where individuals who are heterozygous for a particular gene (i.e. have two different alleles of that gene) have an advantage over homozygote individuals (who have two identical copies of the gene). Heterozygote advantage is responsible for many cases of potentially harmful genes being maintained at a finite frequency in a population.

The classic example of heterozygote advantage is sickle-cell gene, where homozygote individuals suffer anemia while heterozygote individuals benefit from improved malaria resistance. ${ }^{73}$ Heterozygotes have greater fitness than both types of homozygote (those lacking the sickle-cell allele and those having two copies of it). Balancing selection preserves the sickle-cell gene in populations (at a frequency that varies geographically with the prevalence of malaria). The "optimum" that evolution selects is one in which, by chance, some individuals will be born homozygous for the gene, resulting in sickle-cell anemia, a potentially fatal blood disease. The "ideal optimum" - everybody being heterozygous for the gene-is unattainable by natural selection because of Mendelian inheritance, which gives each child born to heterozygote parents a 25 per cent chance of being born homozygous for the sickle-cell allele.

Heterozygote advantage suggests an obvious enhancement opportunity. If possible, the variant allele could be removed and its gene product administered as medication. Alternatively, genetic screening could be used to guarantee heterozygosity, enabling us to reach the ideal optimum that eluded natural selection.

The phenomenon of heterozygote advantage points to potential enhancements beyond reducing susceptibility to diseases such as malaria and sickle-cell anemia. For instance, there is some indirect evidence that at least Type I Gaucher's Disease (and possibly other sphingolipid storage diseases) is linked to improved cognition, given the significantly higher proportion of sufferers in occupations correlated with high IQ. ${ }^{74}$ This, and other circumstantial evidence, is used by the authors of the cited study to argue that heterozygote advantage can explain the high IQ test scores and the high prevalence of Type I Gaucher's Disease among Ashkenazi

\footnotetext{
73 Allison I954; Cavalli-Sforza and Bodmer I999.

${ }^{74}$ Cochran, Hardy and Harpending 2006.
} 
Jews. Should this prediction be borne out by finding an IQ advantage for heterozygote carriers of the diseases, it would suggest that screening to promote heterozygosity, or genetic interventions to induce it, would be viable forms of cognition enhancement that meet the EOC.

One other kind of evolutionary entrapment is worth noting here, that of an evolutionarily stable strategy (ESS), "a strategy such that, if all the members of a population adopt it, no mutant strategy can invade". ${ }^{75}$ One way in which a species can become trapped in an ESS is through sexual selection. In order to be successful at wooing peahens, peacocks have to produce extravagant tails which serve to advertise the male's genetic quality. Only healthy peacocks can afford to produce and carry top-notch tails. It is adaptive for peahens to prefer to mate with peacocks that sport an impressive tail; and given this fact, it is also adaptive for peacocks to invest heavily in their plumage. It is likely that the species would have been better off if it had evolved some less costly way for males to signal fitness. Yet no individual peacock or peahen is able to defect from the ESS without thereby removing themselves from the gene pool. If there had been a United Nations of the peafowl, through which the birds could have adopted a coordinated millennium plan to overcome their species' vanity, the peacocks would surely soon be wearing a more casual outfit.

The concept of an ESS can be generalized to that of an evolutionarily stable state. A population is said to be in an evolutionarily stable state if its genetic composition is restored by selection after a disturbance, provided the disturbance is not too large. ${ }^{76}$ Such a population can be genetically monomorphic or polymorphic. Thus, while ESS refers to a specific strategy that is stable if everybody adopts it, an evolutionary stable state can encompass a set of strategies whose distribution is stable under small perturbations. It has been suggested that the human population has been in a stable state in the EEA with regard to sociopathy, which can be seen as a defector strategy which can prosper when it is rare but becomes maladaptive when it is more common. ${ }^{77}$

Another way in which evolution can fail to produce solutions that are fitness-maximizing for organisms is intragenomic conflict, in which phenomena such as meiotic drive, transposons, homing endonuclease

$$
{ }^{75} \text { Smith 1982. } \quad{ }^{76} \text { Ibid. } \quad{ }^{77} \text { Mealey } 1995 .
$$


genes, B-chromosomes, and plasmids result from natural selection among lower-level units such as individual genes. ${ }^{78}$ In cases where we can identify intragenomic conflict as responsible for a suboptimal outcome, there is an opportunity for enhancement that can meet the EOC (provided we have the technological means to make the requisite interventions). Genes or traits that would not have evolved, or which would not have been stable against intragenomic competition, could be inserted, possibly supported by interventions removing some of the competing genetic elements.

\subsection{Evolutionary lag}

Evolution takes time-often, a long time. If conditions change rapidly, the genome will lag. Given that conditions for humanoid ancestors were quite variable-due to migration into new regions, climate change, social dynamics, advances in tool use, and adaptation in pathogens, parasites, predators, and prey-our species has never been perfectly adapted to its environment. Evolution is running up fitness slopes, but when the fitness landscape keeps changing under its feet, it may never reach a peak. Even if beneficial alleles or allele combinations exist, they may not have had the time to diffuse across human populations. For some proposed enhancements, evolutionary lag can therefore provide an answer to the EOC.

This source of answers to the EOC is related to the changed tradeoffs category, but with the difference that here we are focusing on ways in which even during the EEA we were not perfectly adapted to our environment. Even if we set aside the dramatic ways in which resources and demands have changed since the introduction of agriculture, there may still be instances of earlier evolutionary lags that have not yet been truncated and which may point to opportunities for enhancement.

There are many factors limiting the speed of evolution. ${ }^{79}$ Some are inherent in the process itself, such as the mutation rate, the need for sufficient genetic diversity, and the constraint that selection can only encode a few bits into the genome per generation. ${ }^{80} \mathrm{~A}$ recessive beneficial mutation will spread to an appreciable fraction of a fixed well-mixed population in time inversely proportional to its selective advantage. For

\footnotetext{
${ }_{78}$ Burt and Trivers 2006. $\quad{ }^{79}$ Barton and Partridge 2000. $\quad{ }^{80}$ Worden 1995.
} 


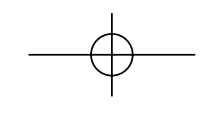

404

example, if the mutation gives a O.I per cent increase in fitness, it will take 9,200 generations (230,000 years assuming 25 years per generation) to reach 50 per cent of the population from a starting level of o.o I per cent. For a IO per cent fitness-advantage, just 92 generations (2,300 years) are needed. ${ }^{81}$ Population structure and especially low-population bottlenecks can accelerate the spread significantly.

In nature, the strength of selection for a trait is generally quite weak. A review of published studies ${ }^{82}$ found the distribution of selection strengths across species to be exponential, with a small median magnitude: for most traits and in most systems directional selection is fairly weak. Selection via survival appears to be weaker than selection through mating success, making sexual selection a big factor. Quadratic selection gradients, indicating the "sharpness" of fitness peaks, were also found to be exponentially distributed and with small median. This implies that stabilizing selection (reducing genetic diversity once a population has reached a local fitness peak) is often fairly weak. Indirect selection (where trait fitness depends on another correlated trait) also appears to be playing only a minor role. ${ }^{83}$ These results suggest that beneficial new traits are likely to spread slowly.

A population living in a heterogeneous or changeable environment may not be able to converge on a single fitness peak but will be spread out around it. This might reduce extinction risks for the lineage, since there will always be some individuals that are well adapted if the conditions change and the lineage will survive more easily than if a less dispersed population had to ascend the current gradient towards the top through a region of low survivability.

It is possible to detect empirically the presence of genetic variations under positive fitness pressure through their signatures. ${ }^{84}$ These signatures range from multimillion-year timescale changes in gene sequence (mostly useful to point out ongoing or recurrent selection), to changes in genetic diversity caused by the rapid spread of a beneficial mutation in the past 250,000 years, to the differences between human populations which can

\footnotetext{
81 Cavalli-Sforza and Bodmer I999.

${ }^{82}$ Hoekstra, Hoekstra, Berrigan, Vignieri, Hoang, Hill, Beerli and Kingsolver $200 \mathrm{I}$.

83 Ibid.

${ }^{84}$ Sabeti, Schaffner, Fry, Lohmueller, Varilly, Shamovsky, Palma, Mikkelsen, Altshuler and Lander 2006.
} 
indicate genetic selection over the last 50,000-75,000 years. Such longterm selection evidence is mainly useful for understanding the selection pressures in the EEA.

There is evidence for recent positive selection in humans. ${ }^{85}$ Some of it may be in response to climate variations, producing a wide range of variation in salt-regulating genes in populations far from the equator. ${ }^{86}$ Genes involved in brain development have also been shown to have been under strong positive selection with new variants emerging over the last 37,000 years ${ }^{87}$ and 5,800 years. ${ }^{88}$

There is evidence that genes related to the brain have evolved more quickly in the human lineage than in other primates and rodents. ${ }^{89}$ The rapid growth of the brain in the human lineage also suggests that its size must be controlled by relatively simple genetic mechanisms..$^{90}$ Despite this, it should be noted that the selection differential per generation for human brain weight during the Pleistocene was only 0.0004 per generation: ${ }^{91}$ even under fast evolution brain size was limited by tradeoffs.

If we find a gene that has a desirable effect, and that evolved recently and has not yet spread far despite showing evidence of positive selection, interventions that insert it into the genome or mimic its effects would likely meet the EOC. A simple example would be lactose tolerance. While development of lactose intolerance is adaptive for mammals since it makes weaning easier, dairy products have stimulated selection for lactase in humans over the last 5,000-10,000 years. ${ }^{92}$ This is so recent that there has not been time for the trait to diffuse to all human populations. (Populations that have domesticated cattle but do not have lactose tolerance instead make use of fermented milk or cheese.) Taking lactase pills enables lactoseintolerant people to digest lactose, widening the range of food they can enjoy. This enhancement clearly passes the EOC.

\footnotetext{
85 Voight, Kudaravalli, Wen and Pritchard 2006.

86 Thompson, Kuttab-Boulos, Witonsky, Yang, Roe and Di Rienzo 2004.

${ }^{87}$ Evans, Gilbert, Mekel-Bobrov, Vallender, Anderson, Vaez-Azizi, Tishkoff, Hudson and Lahn 2005

${ }^{88}$ Mekel-Bobrov, Gilbert, Evans, Vallender, Anderson, Hudson, Tishkoff and Lahn 2005.

${ }^{89}$ Dorus, Vallender, Evans, Anderson, Gilbert, Mahowald, Wyckoff, Malcom and Lahn 2004.

90 Roth and Dicke 2005.

91 Cavalli-Sforza and Bodmer I999, 692

92 Bersaglieri, Sabeti, Patterson, Vanderploeg, Schaffner, Drake, Rhodes, Reich and Hirschhorn 2004; Tishkoff, Reed, Ranciaro, Voight, Babbitt, Silverman, Powell, Mortensen, Hirbo, Osman, Ibrahim, Omar, Lema, Nyambo, Ghori, Bumpstead, Pritchard, Wray and Deloukas 2007.
} 


\section{Discussion}

The evolution heuristic instructs us to consider, for an apparently attractive enhancement, why we have not already evolved the intended trait if it is really such a good idea. We called this question the Evolutionary Optimality Challenge, and we have described three broad categories of possible answers, and given some examples of particular enhancements for which it is possible to meet the EOC, and which, therefore, seem comparatively promising as intervention targets that may be feasible in the relatively near term and which may have on balance beneficial effects.

In general, when we pose the EOC for some particular proposed enhancement, we might discover one of several things:

I. Current ignorance prevents us from forming any plausible idea about the evolutionary factors at play.

2. We come up with a plausible idea about the relevant evolutionary factors, and this reveals that the proposed modification would likely not be a net benefit.

3. We come up with a plausible idea about the relevant evolutionary factors, and this reveals why we would not already have evolved to have the enhanced capacity even if it would be a net benefit.

4. We come up with several plausible but mutually inconsistent ideas about the relevant evolutionary factors.

The first possibility means that we have no clear idea about why, from a phylogenetic perspective, the trait that is the target of the proposed enhancement is the way it is. This should give us pause. If we do not understand why a very complex evolved system has a certain property, there is a considerable risk that something will go wrong if we try to modify it. The case might be one of those where nature does know best. Like an over-ambitious tinkerer with merely superficial understanding of what he is doing while he is making changes to the design of a master craftsman, the potential for damage is considerable and the chances of producing an all-things-considered improvement are small.

We are not claiming that it is always inadvisable to try an intervention when we have no adequate understanding of the subsystem we intend to enhance. We might have other sources of evidence that afford us 
sufficient assurance that the intervention will work and will not cause unacceptable side-effects, even without understanding the evolutionary functions involved. For example, we might have used the intervention many times before and found that it works well. Alternatively, we might have evidence from a closely analogous subsystem, such as an animal model, that suggests that the intervention should work in humans too. In such cases, the evolution heuristic delivers only a weak recommendation: that absent any good answer to the EOC, we should proceed only with great caution. In particular, we should be alert to the possibility that the proposed intervention will turn out to have significant (but perhaps subtle) side-effects.

The second possibility is that we succeed in developing a plausible understanding of the pertinent evolutionary factors, and, having done so, we find our initial hopes about the proposed modification undermined. None of the three categories we have described yields a satisfactory answer to the EOC: the relevant tradeoffs have not changed since the EOC, there is no relevant value discordance, and no evolutionary restriction would have prevented the modification from already having evolved by now. In this case we have strong reason for thinking that the enhancement intervention will fail or backfire. If we proceed, the wisdom of nature will bite us.

The fourth possibility is that we come up with two or more plausible but incompatible evolutionary accounts of the evolutionary factors at play. In this case, we can consider the implications of each of the different evolutionary accounts separately according to the above criteria. If all yield green lights, we are encouraged to proceed. If some of the evolutionary accounts yield green lights but others yield red lights, then we face a situation of uncertainty. We can use standard decision-theory to determine how to proceed-we can take a gamble if we feel that the balance of probabilities sufficiently favor the green lights; if not, we can attempt to acquire more information in order to reduce the uncertainty, or forgo the potential enhancement and try something else.

The evolution heuristic is not a rival method to the more obvious way of determining whether some enhancement intervention works: testing it in well-designed clinical trials. Instead, the heuristic is complementary. It helps us ask some useful questions. By posing the EOC, and carefully searching for and evaluating possible answers in each of the three categories we described, 
we can (a) identify promising candidate enhancement interventions, to be explored further in laboratory and clinical studies, and (b) better evaluate the likelihood that some intervention which has shown seemingly positive results in clinical studies will actually work as advertised and will not have unacceptable side-effects of a hidden, subtle, or long-term nature.

\section{Conclusion}

There is a widespread belief in some kind of "wisdom of nature". Many people prefer "natural" remedies, "natural" food supplements, and "natural" ways of improving human capacities such as training, diet, and grooming. "Unnatural" interventions are often viewed with suspicion, and this attitude seems to be especially pronounced in relation to unnatural ways of enhancing human capacities, which are viewed as unwise, short-sighted, and hubristic. We believe that such attitudes also exert an influence on beliefs about the kind of matters that arise in bioethical discussions of human enhancement.

While it is tempting to dismiss intuitions about the wisdom of nature as vulgar prejudice, we have suggested that these intuitions contain a grain of truth, especially as they pertain to human enhancement. We have attempted to explicate this grain of truth as the Evolutionary Optimality Challenge.

After posing this challenge, the evolution heuristic instructs us to examine three broad categories of potential ways of meeting the challenge: changed tradeoffs, value discordance, and evolutionary restrictions. These categories correspond to systematic limitations in the wisdom of nature idea. For some potential enhancement interventions, the challenge can be met with an answer from one of these categories; for other potential interventions, the challenge cannot be met. The latter interventions merit suspicion, and attempting them may indeed be unwise, short-sighted, and hubristic. The former interventions, in contrast, do not defy the wisdom of nature and have a better chance of working.

By understanding both the sense in which there is validity in the idea that nature is wise and the limits beyond which the idea ceases to be valid, we are in a better position to identify promising human enhancements and to evaluate the risk-benefit ratio of extant enhancements. If we are right in supposing that intuitions about the wisdom of nature exert an inarticulate 
influence on opinion in contemporary bioethics of human enhancement, then the evolution heuristic-while primarily a method for addressing empirical questions - may also help to inform our assessments of more normatively loaded items of dispute. ${ }^{93}$

\section{References}

Aiello, L. C., N. Bates, and T. Joffe. 200I. 'In defense of the Expensive Tissue Hypothesis'. In Evolutionary Anatomy of the Primate Cerebral Cortex. Falk, D. and K. R. Gibson (eds), Cambridge, UK: Cambridge University Press: 57-78.

Allison, A. C. 1954. 'Protection Afforded by Sickle Cell Trait Against Subtertian Malarial Infection', British Medical Journal I: 290-4.

Andersson, R. E., G. Olaison, C. Tysk, and A. Ekbom. 200I. 'Appendectomy and protection against ulcerative colitis', New England Journal of Medicine 344(I I): $808-\mathrm{I} 4$.

Baldwin, K. M. and F. Haddad. 2002. 'Skeletal muscle plasticity-Cellular and molecular responses to altered physical activity paradigms', American Journal of Physical Medicine \& Rehabilitation 8I(I I): $\mathrm{S}_{40} \mathrm{O}-\mathrm{S}_{5} \mathrm{I}$.

Barton, N., and L. Partridge. 2000. 'Limits to natural selection', Bioessays 22(I2): I075-84.

Battista, J. R., A. M. Earl, and M. J. Park. 1999. "Why is Deinococcus radiodurans so resistant to ionizing radiation?', Trends in Microbiology 7(9): $362-5$.

Beauchamp, T. L., and J. F. Childress. 1979. Principles of Biomedical Ethics. New York and Oxford: Oxford University Press.

Bersaglieri, T., P. C. Sabeti, N. Patterson, T. Vanderploeg, S. F. Schaffner, J. A. Drake, M. Rhodes, D. E. Reich, and J. N. Hirschhorn. 2004. 'Genetic signatures of strong recent positive selection at the lactase gene', American Journal of Human Genetics 74(6): I I I I-20.

Boon, T. and N. van Baren. 2003. 'Immunosurveillance against cancer and immunotherapy-synergy or antagonism?', New England Journal of Medicine $348(3): 252-4$.

Brunswick, N., G. N. Martin, L. Marzano, and N. Savill. 2007. 'Visuo-spatial ability, handedness and developmental dyslexia: Just how sinister was Andy Warhol?' Presentation to the 25th European Workshop on Cognitive Neuropsychology, Italy 2007.

93 For their comments, we are grateful to Rebecca Roache for helpful comments on an earlier draft of this paper, and to the audience at the TransVision 2006 conference in Helsinki, Finland, for useful questions. 
Bunker, J. P. 200I. 'The role of medical care in contributing to health improvements within societies', Int. J. Epidemiol. 30(6): 1260-3.

Burt, A., and R. L. Trivers. 2006. Genes in Conflict: The Biology of Selfish Genetic Elements. Harvard: Belknap Press.

Buss, D. M. 2000. 'The evolution of happiness', American Psychologist 55(I): I 5-23.

Caldwell, J. A. 200I. 'Efficacy of stimulants for fatigue management: The effects of Provigil and Dexedrine on sleep-deprived aviators', Fatigue in Transportation (Part F): 19-37.

Cavalli-Sforza, L. L., and W. F. Bodmer. 1999. The Genetics of Human Populations, New York: Dover Publications.

Cochran, G., J. Hardy, and H. Harpending. 2006. 'Natural History of Ashkenazi Intelligence', Journal of Biosocial Science 38(5): 659-93.

Colloca, L., and F. Benedetti. 2005. 'Placebos and painkillers: is mind as real as matter?', Nature Reviews Neuroscience 6(7): 545-52.

Dawkins, R. I976. The Selfish Gene. Oxford: Oxford University Press.

de Murcia, G., and S. Shall (eds.), 2000. From DNA Damage and Stress Signaling to Cell Death: Poly ADP-Ribosylation Reactions. Oxford: Oxford University Press.

Demas, G. E., V. Chefer, M. I. Talan, and R. J. Nelson. I997. 'Metabolic costs of mounting an antigen-stimulated immune response in adult and aged $\mathrm{C}_{57} \mathrm{BL} / 6 \mathrm{~J}$ mice', American Journal of Physiology-Regulatory Integrative and Comparative Physiology 42(5): Rir63 I-R7.

Diener, E., E. M. Suh, R. E. Lucas, and H. L. Smith. I999. 'Subjective well-being: Three decades of progress', Psychological Bulletin I25(2): 276-302.

Dorus, S., E. J. Vallender, P. D. Evans, J. R. Anderson, S. L. Gilbert, M. Mahowald, G. J. Wyckoff, C. M. Malcom, and B. T. Lahn. 2004. 'Accelerated evolution of nervous system genes in the origin of Homo sapiens', Cell I I9(7): I027-40.

Dunn, G. P., L. J. Old, and R. D. Schreiber. 2004. 'The immunobiology of cancer immunosurveillance and immunoediting', Immunity 2 I (2): I37-48.

Elia, M. I992. 'Organ and tissue contribution to metabolic rate', Energy metabolism: tissue determinants and cellular corollaries. McKinney, J. M. and H. N. Tucker (eds). New York: Raven, 6I-79.

Evans, P. D., S. L. Gilbert, N. Mekel-Bobrov, E. J. Vallender, J. R. Anderson, L. M. Vaez-Azizi, S. A. Tishkoff, R. R. Hudson, and B. T. Lahn. 2005. 'Microcephalin, a gene regulating brain size, continues to evolve adaptively in humans', Science 309(574I): I7I7-20.

Fairclough, S. H., and K. Houston. 2004. 'A metabolic measure of mental effort', Biological Psychology 66(2): I77-90.

Farah, M. J., J. Illes, R. Cook-Deegan, H. Gardner, E. Kandel, P. King, E. Parens, B. Sahakian, and P. R. Wolpe. 2004. 'Neurocognitive enhancement: what can we do and what should we do?', Nature Reviews Neuroscience 5(5): 42 I. 
Fish, J. L., and C. A. Lockwood. 2003. 'Dietary constraints on encephalization in primates', American Journal of Physical Anthropology I20(2): I7I-8I.

Fisher, R. E. 200o. 'The primate appendix: A reassessment', Anatomical Record $26 \mathrm{I}(6): 228-36$

Flegal, K. A., B. I. Graubard, D. F. Williamson, and M. H. H. Gail. 2005. 'Excess deaths associated with underweight, overweight, and obesity', Jama-Journal of the American Medical Association 293(I5): I86I-7.

Fontaine, K. R., D. T. Redden, C. X. Wang, A. O. Westfall, and D. B. Allison. 2003. 'Years of life lost due to obesity', Jama-Journal of the American Medical Association 289(2): 187-93.

Force, U. S. P. S. T. 2002. 'Aspirin for the primary prevention of cardiovascular events: recommendation and rationale', Annals of Internal Medicine I36(2): I $57-60$.

Frech, H. E., and R. D. Miller. I996. 'The Productivity of Health Care and Pharmaceuticals: An International Comparison'. UCLA Research Program in Pharmaceutical Economics and Policy 97-I. http://repositories.cdlib.org/ pep/97-I/

Freitas, R. A., Jr. I998. 'Exploratory Design in Medical Nanotechnology: A Mechanical Artificial Red Cell', Artificial Cells, Blood Substitutes, and Immobilization Biotechnology 26: 4I I-30.

Gaesser, G. A. I999. 'Thinness and weight loss: beneficial or detrimental to longevity?', Medicine and Science in Sports and Exercise 3 I(8): I I 8-28.

Goldspink, G. 2005. 'Mechanical signals, IGF-I gene splicing, and muscle adaptation', Physiology 20: 232-8.

Gottfredson, L. S. I997. 'Why g matters: The complexity of everyday life', Intelligence 24(I): 79- 132 .

2004. 'Life, death, and intelligence', Journal of Cognitive Education and Psychology $4(\mathrm{I}): 23-46$.

2007. 'Innovation, fatal accidents, and the evolution of general intelligence'. In M. J. Roberts (ed.), Integrating the mind: Domain general vesus domain specific process in higher cognition, Hove: UK Psychology Press, 387-425.

Goulandris, N. K., M. J. Snowling, and I. Walker. 200o. 'Is dyslexia a form of specific language impairment? A comparison of dyslexic and language impaired children as adolescents', Annals of Dyslexia L: 103-20.

Green, C. S., and D. Bavelier. 2006. 'Enumeration versus multiple object tracking: the case of action video game players', Cognition IOI(I): 2 I 7-45.

Hagen, E. H. 2002. 'What is the EEA?' (detailed answer), Evolutionary Psycho$\log \gamma$ FAQ, retrieved 2 July, 2006, from http://www.anth.ucsb.edu/projects/ human/epfaq/eea2.html. 
Hammerstein, P. I996. 'Darwinian adaptation, population genetics and the streetcar theory of evolution', Journal of Mathematical Biology 34(5-6): 5I I-32.

Hoekstra, H. E., J. M. Hoekstra, D. Berrigan, S. N. Vignieri, A. Hoang, C. E. Hill, P. Beerli, and J. G. Kingsolver. 200I. 'Strength and tempo of directional selection in the wild', Proc. Natl. Acad. Sci. USA 98(г6): 91 57-60.

Holliday, M. A. I986. 'Body composition and energy needs during growth', Human Growth: A Comprehensive Treatise. Falkner, F. and J. M. Tanner (eds). New York: Plenum Press, IOI-I7.

House, J. S., K. R. Landis, and D. Umberson. I988. 'Social relationships and health', Science 24I (4865): 540-5.

Hubbard, E. M., M. Piazza, P. Pinel, and S. Dehaene. 2005. 'Interactions between number and space in parietal cortex', Nature Reviews Neuroscience 6(6): 435-48.

Humphrey, Nicholas, 2002. 'Great Expectations: The Evolutionary Psychology of Faith-healing and the Placebo Response'. In Psychology at the Turn of Millennium, vol. 2: Social, Developmental, and Clinical Perspectives. Hofsten, C. and L. Bäckman (eds). Hove: Psychology Press, 225-46.

Jensen, P. S., D. Mrazek, P. K. Knapp, L. Steinberg, C. Pfeffer, J. Schowalter, and T. Shapiro. I997. 'Evolution and revolution in child psychiatry: ADHD as a disorder of adaptation', Journal of the American Academy of Child and Adolescent Psychiatry 36(I2): I672-9.

Kiecolt, J. K., R. Glaser, J. T. Cacioppo, R. C. MacCallum, M. Snydersmith, C. Kim, and W. B. Malarkey. I997. 'Marital conflict in older adults: Endocrinological and immunological correlates', Psychosomatic Medicine 59(4): 339-49.

Kirsch, I., T. J. Moore, A. Scoboria, and S. S. Nicholls. 2002. 'The Emperor's New Drugs: An Analysis of Antidepressant Medication Data Submitted to the US Food and Drug Administration', Prevention \& Treatment, 5.

Klaus, T., R. Joerger, E. Olsson, and C. G. Granqvist. I999. 'Silver-based crystalline nanoparticles, microbially fabricated', Proc. Natl. Acad. Sci. USA 96(24): I36I I-I4.

Korol, D. L., and P. E. Gold. I998. 'Glucose, memory, and aging', American Journal of Clinical Nutrition 67(4): 764S-7IS.

Koutroubakis, I. E., and I. G. Vlachonikolis. 2000. 'Appendectomy and the development of ulcerative colitis: Results of a metaanalysis of published casecontrol studies', American Journal of Gastroenterology 95(I): I7 I-6.

Leroi, A. M., A. Bartke, G. De Benedictis, C. Franceschi, A. Gartner, E. S. Gonos, M. E. Fedei, T. Kivisild, S. Lee, N. Kartaf-Ozer, M. Schumacher, E. Sikora, E. Slagboom, M. Tatar, A. I. Yashin, J. Vijg, and B. Zwaan. 2005. 'What evidence is there for the existence of individual genes with antagonistic pleiotropic effects?' Mechanisms of Ageing and Development I 26(8): 42 I-9. 
Maizels, R. M. 2005. 'Infections and allergy — helminths, hygiene and host immune regulation', Current Opinion in Immunology I7(6): 656-6I.

Manning, C. A., W. S. Stone, D. L. Korol, and P. E. Gold. I998. 'Glucose enhancement of 24-h memory retrieval in healthy elderly humans', Behavioural Brain Research 93(I-2): 7I-6.

Martin, L. B., 2nd, A. Scheuerlein, and M. Wikelski. 2003. 'Immune activity elevates energy expenditure of house sparrows: a link between direct and indirect costs?', Proc. Biol. Sci. 270(I5 I I): I 53-8.

Martin, P. Y., and D. Benton. I999. 'The influence of a glucose drink on a demanding working memory task', Physiology and Behavior 67(I): 69-74.

Martin, R. D. I996. 'Scaling of the mammalian brain: The maternal energy hypothesis', News in Physiological Sciences I I: 149-56.

Matte, T. D. 200I. 'Influence of variation in birth weight within normal range and within sibships on IQ at age 7 years: cohort study', British Medical Journal 323(73 I 4): 3 IO-I4.

McCord, J. M. 2000. 'The evolution of free radicals and oxidative stress', Am. J. Med. Io8(8): 652-9.

McDade, T. W. 2002. 'Status incongruity in Samoan youth: a biocultural analysis of culture change, stress, and immune function', Medical Anthropology Quarterly I6(2): I $23-50$.

2003. 'Life History Theory and the Immune System: Steps Toward a Human Ecological Immunology', Yearbook of Physical Anthropology 46: I00-25.

McDaniel, M. A. 2005. 'Big-brained people are smarter: A meta-analysis of the relationship between in vivobrain volume and intelligence', Intelligence 33(4): $337-46$.

McKeown, T., and C. R. Lowe. I974. An Introduction to Social Medicine. Oxford: Blackwell Scientific.

Mealey, L. I995. 'The Sociobiology of Sociopathy — an Integrated Evolutionary Model', Behavioral and Brain Sciences I 8(3): 523-4I.

Meikle, A., L. M. Riby, and B. Stollery. 2005. 'Memory processing and the glucose facilitation effect: the effects of stimulus difficulty and memory load', Nutritional Neuroscience 8(4): 227-32.

Mekel-Bobrov, N., S. L. Gilbert, P. D. Evans, E. J. Vallender, J. R. Anderson, R. R. Hudson, S. A. Tishkoff, and B. T. Lahn. 2005. 'Ongoing adaptive evolution of ASPM, a brain size determinant in Homo sapiens', Science 309(574I): I $720-2$.

Merkle, R. C., and R. A. Freitas. 2003. 'Theoretical analysis of a carbon-carbon dimer placement tool for diamond mechanosynthesis', Journal of Nanoscience and Nanotechnology 3(4): 3 I9-24. 


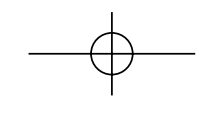

4I 4 NICK BOSTROM \& ANDERS SANDBERG

Moret, Y., and P. Schmid-Hempel. 2000. 'Survival for immunity: the price of immune system activation for bumblebee workers', Science 290(5494): I I66-8.

Neisser, U., G. Boodoo, T. J. Bouchard, A. W. Boykin, N. Brody, S. J. Ceci, D. F. Halpern, J. C. Loehlin, R. Perloff, R. J. Sternberg, and S. Urbina. 1996. 'Intelligence: Knowns and unknowns', American Psychologist 5I(2): 77-IOI.

Nesse, R. M., and G. C. Williams. I998. 'Evolution and the origins of disease', Scientific American 279(5): 86-93.

Newhouse, J. P., and T. I. E. Group. I993. Free for All? Lessons from the RAND Health Insurance Experiment. Cambridge, Mass.: Harvard University Press.

Niven, J. E. 2005. 'Brain evolution: Getting better all the time?', Current Biology I 5(I6): R624-R6.

Nutt, D. J. 2006. 'Alcohol alternatives - a goal for psychopharmacology?', Journal of Psychopharmacology 20(3): 3 I 8-20.

Oria, R. B., P. D. Patrick, H. Zhang, B. Lorntz, C. M. D. Costa, G. A. C. Brito, L. J. Barrett, A. A. M. Lima, and R. L. Guerrant. 2005. 'APOE4 protects the cognitive development in children with heavy diarrhea burdens in northeast Brazil', Pediatric Research 57(2): 3 Io- I6.

Ots, I., A. B. Kerimov, E. V. Ivankina, T. A. Ilyina, and P. Horak. 200 I. 'Immune challenge affects basal metabolic activity in wintering great tits', Proc. Biol. Sci. 268(I472): I I75-8I.

Parker, G. A. and J. M. Smith. I990. 'Optimality Theory in Evolutionary Biology', Nature 348(6296): 27-33.

Pica, P., C. Lemer, V. Izard, and S. Dehaene. 2004. 'Exact and Approximate Arithmetic in an Amazonian Indigene Group', Science 306(5695): 499-503.

Roth, G., and U. Dicke. 2005. 'Evolution of the brain and intelligence', Trends in Cognitive Sciences 9(5): 250-7.

Sabeti, P. C., S. F. Schaffner, B. Fry, J. Lohmueller, P. Varilly, O. Shamovsky, A. Palma, T. S. Mikkelsen, D. Altshuler, and E. S. Lander. 2006. 'Positive natural selection in the human lineage', Science 3 I2(5780): I6I4-20.

Sapolsky, R. M. 2005. 'The influence of social hierarchy on primate health', Science 308(5722): 648-52.

Sauro, M. D., and R. P. Greenberg. 2005. 'Endogenous opiates and the placebo effect: a meta-analytic review', Journal of Psychosomatic Research 58(2): I I 5-20.

Scholey, A. B., S. Harper, and D. O. Kennedy. 200I. 'Cognitive demand and blood glucose', Physiology and Behavior 73(4): 585-92.

Siegel, J. M. 2005. 'Clues to the functions of mammalian sleep', Nature 437(7063): I $264-7 \mathrm{I}$.

Silberman, S. 200 . 'The Geek Syndrome', Wired 9(12). 
Skaper, S. D. 2003. 'Poly(ADP-ribosyl)ation enzyme-I as a target for neuroprotection in acute central nervous system injury', Curr. Drug Targets, CNS Neurol. Disord. 2(5): 279-9I.

Smith, J. M. I982. Evolution and the Theory of Games. Cambridge, UK: Cambridge University Press.

Starfield, B. 2000. 'Is US health really the best in the world?', Jama-Journal of the American Medical Association 284(4): 483-5.

Thomas, M. K., D. M. Lloyd-Jones, R. I. Thadhani, A. C. Shaw, D. J. Deraska, B. T. Kitch, E. C. Vamvakas, I. M. Dick, R. L. Prince, and J. S. Finkelstein. I998. 'Hypovitaminosis D in medical inpatients', New England Journal of Medicine 338(I 2): $777-83$.

Thompson, E. E., H. Kuttab-Boulos, D. Witonsky, L. Yang, B. A. Roe, and A. Di Rienzo. 2004. ' $\mathrm{CYP}_{3} \mathrm{~A}$ variation and the evolution of salt-sensitivity variants', American Journal of Human Genetics 75(6): 1059-69.

Tishkoff, S. A., F. A. Reed, A. Ranciaro, B. F. Voight, C. C. Babbitt, J. S. Silverman, K. Powell, H. M. Mortensen, J. B. Hirbo, M. Osman, M. Ibrahim, S. A. Omar, G. Lema, T. B. Nyambo, J. Ghori, S. Bumpstead, J. K. Pritchard, G. A. Wray, and P. Deloukas. 2007. 'Convergent adaptation of human lactase persistence in Africa and Europe', Nature Genetics 39(I): 3 I - 40.

Trevathan, W. 1987. Human Birth: An Evolutionary Perspective. New York: Aldine de Gruyter.

Trevathan, W. R., E. O. Smith, and J. J. McKenna (eds.), I999. Evolutionary Medicine. Oxford: Oxford University Press.

Udry, J. R. I978. 'Differential Fertility by Intelligence-Role of Birth Planning', Social Biology 25(I): IO-I4.

Vancourt, M., and F. D. Bean. I985. 'Intelligence and Fertility in the United States-I9I2-I982, Intelligence 9(I): 23-32.

Venkateswaran, A., S. C. McFarlan, D. Ghosal, K. W. Minton, A. Vasilenko, K. Makarova, L. P. Wackett, and M. J. Daly. 2000. 'Physiologic Determinants of Radiation Resistance in Deinococcus radiodurans', Applied and Environmental Microbiology 66(6): 2620-6.

Vining, D. R., L. Bygren, K. Hattori, S. Nystrom, and S. Tamura. I988. 'IQ/Fertility Relationships in Japan and Sweden', Personality and Individual Differences 9(5): $93 \mathrm{I}-2$.

Voight, B. F., S. Kudaravalli, X. Q. Wen, and J. K. Pritchard. 2006. 'A map of recent positive selection in the human genome', Plos Biology 4(3): 446-58.

von Karolyi, C., E. Winner, W. Gray, and G. F. Sherman. 2003. 'Dyslexia linked to talent: Global visual-spatial ability', Brain and Language 85(3): 427-3 I. 


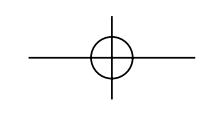

\section{I6 NICK BOSTROM \& ANDERS SANDBERG}

Waterlow, J. C. I984. 'Protein turnover with special reference to man', Q. J. Exp. Physiol. 69(3): 409-38.

Williams, G. C. I996/1966. Adaptation and Natural Selection. Princeton, NJ: Princeton University Press.

and R. M. Nesse. I99I. 'The Dawn of Darwinian Medicine', Quarterly Review of Biology 66(I): I-22.

Winder, R., and J. Borrill. I998. 'Fuels for memory: the role of oxygen and glucose in memory enhancement', Psychopharmacology I36(4): 349-56.

Wood, R. D., M. Mitchell, J. Sgouros, and T. Lindahl. 200I. 'Human DNA repair genes', Science 29I(5507): I284-9.

Worden, R. P. I995. 'A Speed Limit for Evolution', Journal of Theoretical Biology I76(I): I37-52.

Yazdanbakhsh, M., P. G. Kremsner, and R. van Ree. 2002. 'Immunology_Allergy, parasites, and the hygiene hypothesis', Science 296(5567): 490-4.
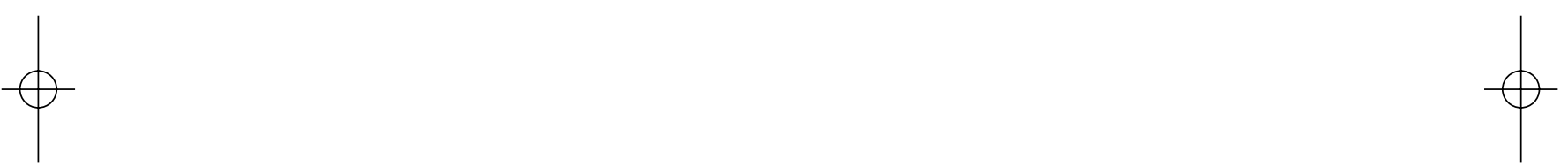